\title{
Implicações do uso do álcool na comunidade indígena Potiguara
}

\section{1 Juliana Rízia Félix de Melo, 2 Silvana Carneiro Maciel, \\ ${ }^{3}$ Rita de Cassia Cordeiro de Oliveira, ${ }^{4}$ Antonia Oliveira Silva I}

Resumo: Em função do crescimento do uso e do abuso do álcool nas populações indígenas do Brasil, esta pesquisa se propôs a investigar o consumo do álcool na comunidade Potiguara do Estado da Paraíba, devido à especificidade cultural e regional desta etnia. Trata-se de um estudo de campo exploratório. A amostra foi composta por 55 índios, maiores de 18 anos e de ambos os sexos. O instrumento utilizado foi uma entrevista semiestruturada aplicada individualmente. Para a análise dos dados, foi utilizado o software SPSS e Análise de Conteúdo Temática. Os resultados revelaram que $41,8 \%$ da amostra estudada têm, pelo menos, um membro da família que faz uso de bebida alcoólica, em sua maioria destiladas, e que o uso ocorre em idade precoce, estando desvinculado da cultura e de rituais. Dos entrevistados 27,3\% afirmaram que a bebida traz diversos problemas para toda a família, inclusive com a morte. Pode-se concluir que, na população indígena estudada, o consumo de bebidas alcoólicas já ocorre de forma abusiva e precoce, necessitando-se de um trabalho mais efetivo de prevenção e de resgate da cultura desta comunidade.

Palavras-chave: saúde indígena; alcoolismo; índios Potiguara; condiçõos sociais; cultura.

\author{
1 Graduanda em Psicologia pela \\ UFPB e aluna bolsista do PIBIC/ \\ CNPq. Endereço eletrônico: \\ julianarizia@hotmail.com \\ 2 Psicóloga, professora adjunta \\ do Departamento de Psicologia \\ da UFPB. Doutora em Psicologia \\ Social UFPBIUFRN. Endereço \\ eletrônico: silcamaciel@ig.com.br \\ ${ }^{3}$ Enfermeira Sanitarista da \\ Fundação Nacional de Saúde, \\ Mestra em Enfermagem pela \\ UFPB. Endereço eletrônico: \\ ritaoliver2002@yahoo.com.br \\ ${ }^{4}$ Enfermeira, Doutora em \\ Enfermagem pela Universidade \\ de São Paulo. Coordenadora do \\ Programa de Pós-Graduação \\ em Enfermagem, Professora \\ Associada II da Universidade \\ Federal da Paraíba/Centro de \\ Ciências da Saúde. Endereço \\ eletrônico: alfaleda@hotmail.com
}

Recebido em: 27/11/2009 Aprovado em: 28/05/2010 


\section{Introdução}

O processo de pacificação/aculturação da população indígena resultou na perda numerária e simbólica da sua cultura, pois a morte de muitos integrantes do grupo, sobretudo dos mais velhos, resultou na subtração de conhecimentos e atividades ritualistas centrais para a manutenção dos costumes. Neste processo colonizador, observa-se a utilização da bebida destilada como forma de aliciamento dos índios pelos dominadores, associado ao uso não ritualístico do álcool (LANGDON, 2001).

No que concerne às populações indígenas, sabe-se que antes da colonização o álcool era consumido de forma tradicional, controlado pelos rituais e pelas cerimônias e em situaçôes de consumo coletivo, como festas, tanto profanas quanto religiosas, comemorações das colheitas e na realização de trabalhos comunitários. Nessas ocasiōes, era permitido "beber até cair", sendo este comportamento considerado como aceitável e tendo prazo para terminar, geralmente no final do ritual ou das festividades. Diferentemente da dependência alcoólica, que gera um aspecto desagregador, esses momentos eram integradores e reforçadores de laços sociais e reciprocidades entre os grupos (OLIVEIRA, 2001).

Associado a esta questão, observa-se também o abandono do uso artesanal do álcool e a propagação das bebidas destiladas, com teor alcoólico mais elevado. A fabricação do álcool passou a ser feita de modo industrial, em grandes quantidades e preços mais baixos. Esses fatores associados fizeram com que este produto ficasse mais acessível à população, aumentando os problemas decorrentes do seu uso excessivo (LARANJEIRA; PINSKY, 2000).

De acordo com Assis (2007), o problema do uso excessivo do álcool ocorre em maior proporção em populações em processo de imposição cultural. É o que acontece com as populaçôes imigrantes e os grupos étnicos diferentes, como é o caso dos indígenas, quando comparados com a sociedade envolvente.

Analisando estas questóes, Langdon (2001, p. 87) afirma que o aumento assustador do consumo de álcool e de alcoolismo entre os índios do Brasil ocorre devido ao fato de que:

Para muitos destes grupos, as tradições de beber mudaram, ou pelo menos os padrões de consumo têm sido influenciados significativamente pela introdução das bebidas destiladas, pelo processo de pacificação, e pela inserção do índio na sociedade envolvente.

Palitot (2005) destaca que, no caso específico dos Potiguara, além de todas as questôes advindas com o processo de aculturação, esta comunidade está situada 
próxima a engenhos e usinas de álcool, facilitando o acesso e o uso abusivo de bebidas alcoólicas. Além disso, por se encontrarem em uma área litorânea, os Potiguaras passaram a conviver com o turismo desordenado, o que contribuiu para a instalação de bares e restaurantes dentro das aldeias. Além de favorecerem o cultivo de hábitos e costumes diferentes, essas invasões desencadearam, principalmente, a transmissão de doenças sexualmente transmissíveis (DST/ Aids) e o adoecimento psíquico. Outro fator de agravamento para o uso abusivo de bebidas, transmissão de doenças e mudanças de hábitos, entre outros, se deve à presença de não-indígenas residindo nas aldeias.

Com base nessas considerações, a presente pesquisa teve como objetivo a obtenção de dados a respeito do uso/abuso do álcool na população indígena Potiguara, com o intuito de contribuir para o aumento de conhecimentos desta população e auxiliar os órgãos competentes na implantação de serviços de atenção básica à saúde nessa comunidade indígena, sobretudo no que se refere ao uso abusivo do álcool e mudanças culturais.

\section{Fundamentação teórica}

De acordo com Lins e Vasconcelos (2004), a questão do índio no Brasil é um tema recorrente e marcado por lutas e movimentos de resistência, com a finalidade da retomada dos territórios tradicionais dos povos indígenas e da defesa da sua identidade cultural. É uma realidade que se choca com o que é ensinado nas escolas de ensino fundamental e nos livros didáticos, onde predomina uma visão romantizada dos índios, caracterizados como pessoas que andam nuas, moram em ocas, veneram o deus Tupã e falam a língua tupi. Atualmente, a maioria dos índios possui um contato avançado com a sociedade envolvente, como é o caso dos índios nordestinos, que desconhecem a língua materna, utilizam o português e vivenciam situações semelhantes às da população carente em geral. Doenças como tuberculose, parasitas intestinais, Aids, desnutrição, problemas dentários, alta taxa de mortalidade infantil, alcoolismo e baixa expectativa de vida fazem parte dessa realidade (LANGDON, 2007).

O contato com os colonizadores resultou numa drástica redução do número dos povos indígenas, a partir das prisões a que estavam sujeitos, da escravidão à qual eram submetidos e da proliferação de epidemias, que dizimaram etnias inteiras. Os índios que sobreviveram puderam experienciar um processo de 
transformação cultural e social, que tinha como pano de fundo uma realidade precária, constituída de péssimas condiçôes de vida (OLIVEIRA, 2001). Entre os prejuízos sofridos pelos indígenas, deve-se incluir a destruição das autoridades tradicionais (como pajés, curandeiros), as quais perderam poder e controle, o que enfraqueceu a organização sociopolítica existente. Desde então, não foi estabelecido nenhum mecanismo de controle social capaz de regular o comportamento dos índios (ASSIS, 2007).

Esse fato também foi observado na etnia Potiguara. Segundo Moonen (2008), os índios da etnia Potiguara, no Estado da Paraíba, vivem numa situação precária de saúde, habitação, vestuário, alimentação e assistência médico-sanitária. Os índios Potiguara constituem o único povo indígena oficialmente reconhecido no Estado da Paraíba, sendo um dos maiores do Brasil e o maior do nordeste etnográfico. Sua população é de 13.790 índios, dos quais 2.061 são desaldeados, residindo em outras cidades do estado. Os demais, 11.729 aldeados, estão distribuídos em 29 aldeias, nos municípios de Baía da Traição, Marcação e Rio Tinto. Observa-se uma dispersão desta população, indo de encontro à ideia de isolamento que permeia ainda o imaginário popular. Essa dispersão torna as ações em prol dos índios mais complicadas, uma vez que dificulta sua delimitação efetiva (FUNASA, 2007).

Diante da dispersão e da aproximação das aldeias com a área urbana dos municípios, diversos fatores nos âmbitos sociais, econômicos, culturais e educacionais vêm contribuindo para a aculturação e despersonalização dessa etnia. Além do mais, o território Potiguara situa-se no meio do caminho entre duas capitais, abriga uma colônia de pescadores, tem linhas diárias de ônibus ligando a região ao Brejo paraibano e à capital; existem também as rotas turísticas que saem das cidades com direção às aldeias para comprar artesanato ou fazer turismo nas praias.

Diante dessas questôes e da teia de pulverização do mundo globalizado e tecnológico, a etnia Potiguara acaba introjetando hábitos e costumes diferentes dos seus, propiciando o aparecimento de doenças, como destaca Coimbra (2000), sendo o alcoolismo uma das mais frequentes.

No ano de 1967 e a partir da 8a Conferência Mundial de Saúde, o tema específico do alcoolismo foi incorporado à Classificação Internacional das Doenças (CID), como Síndrome de Dependência de Álcool, a qual é considerada 
um conjunto de fenômenos fisiológicos, cognitivos e comportamentais, no qual a utilização do álcool se torna prioridade na vida de um indivíduo.

Bertolote (1997) aponta que ocorreu uma evolução no conceito de alcoolismo, pois era considerado como um fenômeno meramente orgânico, enfatizandose apenas as complicaçôes físicas causadas pelo seu uso abusivo; contudo, atualmente é considerado um fenômeno físico, psicológico e social, inserindo-se numa perspectiva histórica e cultural.

De acordo com a FUNASA (2000), o alcoolismo está entre as enfermidades mais comuns nos grupos indígenas brasileiros, com destaque para as regiōes Nordeste, Centro-Oeste, Sudeste e Sul, tendo como agravante a aproximação das populações indígenas das não-indígenas. $\mathrm{O}$ contato interétnico, segundo Souza e Garnelo (2007), iniciou-se há mais de três séculos e propiciou a introdução da bebida destilada na comunidade indígena, favorecendo mudanças na organização destas sociedades, com modificaçôes mais amplas na cultura indígena.

Dados da Organização Mundial de Saúde (OPAS/OMS, 2001) revelam que o alcoolismo afeta cerca de $10 \%$ da população mundial; mas, no que se refere à população indígena, Aguiar e Souza (2001) relatam que a proporção do consumo de bebidas por indígenas é maior do que o da população não indígena, encontrando dados em população aldeada no Mato Grosso do Sul de até $17,6 \%$. Assim, a bebida alcoólica ocupa lugar cada vez mais destacado no campo psíquico dos índios, tanto no âmbito intragrupal, quanto no aspecto intergrupal. Como afirmam Souza e Garnelo (2007), além do caxiri (bebida indígena artesanal), a cachaça, o álcool de uso doméstico, o desodorante e o perfume também são utilizados pela população indígena. Isto demonstra que, na comunidade indígena, o álcool já está distanciado da cultura e dos rituais, tendo hoje um consumo abusivo, com todas as consequências que esse excesso acarreta.

Conforme advertem Souza e Garnelo (2007), há necessidade de contextualizar o uso do álcool na cultura e na história, e não apenas no estudo dos alcoólicos dependentes. Portanto, deve-se procurar o que o ato de beber significa em um determinado tempo e grupo social. Dentro desta perspectiva, Assis (2007, p. 111) afirma:

O ambiente social e cultural é provavelmente a mais importante influência sobre o ato de beber, pois condiciona o tipo de bebida a ser consumida, como se bebe, onde beber, com quem beber, como se comportar e o que se espera de quem bebe. $\mathrm{O}$ ambiente inclui fatores como o que as pessoas pensam e crêem sobre o álcool, as regras 
locais e, além disso, quanto beber, como conseguir e utilizar a bebida. $\mathrm{O}$ ambiente social e cultural faz toda a diferença. Isto pode causar maior ou menor dificuldade para a pessoa tornar-se ou não dependente do álcool.

Observa-se que a questão do alcoolismo nas comunidades indígenas representa um reflexo, uma resposta a um problema coletivo, causado por uma dinâmica social de desconstrução de uma cultura específica, como consequência da aculturação da população indígena. Na concepção de Langdon (2001), há desconhecimento e falta de estudos que dimensionem o consumo de bebidas alcoólicas na população indígena, ocasionando, assim, limitações no desenvolvimento de ações preventivas e de propostas de trabalho adequadas à população indígena.

Devido a estas questôes e à especificidade cultural da etnia Potiguara, faz-se necessário desenvolver um estudo acerca do uso do álcool nesta comunidade, buscando-se entender a especificidade cultural dos Potiguara, assim como o significado do beber para esta etnia.

\section{Método}

Trata-se de uma pesquisa de campo exploratória. A amostra compreendeu 55 índios maiores de 18 anos e de ambos os sexos. Foram sorteadas, ao acaso, 55 famílias, sendo entrevistado um membro por família. Como parâmetro, foi utilizada uma tabela de números aleatórios simples, para a seleção e identificação da família no cadastro do Sistema de Informação de Atenção à Saúde Indígena (SIASI).

O estudo foi realizado na aldeia São Francisco, situada no município de Baía da Traição, na Paraíba. Esta aldeia foi indicada para o cenário do estudo em virtude de manter as tradições indígenas em relação à sua distribuição étnica e cultural. Ela é considerada como uma das maiores aldeias quanto ao número de índios, com 208 famílias cadastradas no SIASI, totalizando 948 índios residentes. Destes, 315 são do sexo masculino e 306 do sexo feminino, acima de 15 anos (FUNASA, 2008).

A coleta de dados foi realizada a partir de uma entrevista individual, seguindo um roteiro semiestruturado e previamente elaborado, com questôes relativas à temática e às características sociodemográficas dos participantes. Para o registro das informaçôes, foi utilizado um gravador de voz digital, desde que permitido pelos índios, após o devido esclarecimento, com a leitura e entrega do Termo 
de Consentimento Livre Esclarecido. A pesquisa seguiu as determinações da Instrução Normativa 01/95/FUNAI/PRESI (FUNAI, 1995) e as prescrições éticas contempladas nas Resoluçôes nos 196/1996 e 304/2000 do Conselho Nacional de Saúde (CNS), que tratam da ética em pesquisas envolvendo seres humanos e da temática especial referente à população indígena (BRASIL, 1996; 2000). Houve a aprovação do Comitê de Ética em Pesquisa do Hospital Universitário Lauro Wanderley, da Universidade Federal da Paraíba/UFPB (CEP/HULW protocolo No 05/2008). O tratamento dos dados foi efetuado pelo software Statistical Package for the Social Sciences (SPSS), versão Windows 15 e através da Análise de Conteúdo Temática (BARDIN, 1977).

\section{Resultados e discussão}

A caracterização dos participantes foi feita levando-se em conta as variáveis sociodemográficas, econômicas e culturais. Assim, pode-se observar que o sexo feminino representou $80 \%$ da amostra estudada. Este alto percentual feminino na amostra pode ter ocorrido pelo fato de as entrevistas terem sido realizadas nas residências, no horário diurno (horário de trabalho formal ou informal). Este resultado corrobora os dados obtidos por várias outras pesquisas, demonstrando que, na atual sociedade, as mulheres ainda permanecem mais tempo em casa, sendo responsáveis pelo trabalho doméstico, enquanto que o homem sai em busca de trabalho e de dinheiro, sendo considerado o mantenedor da casa (CARLOS, 2006).

Quanto à idade, constata-se uma predominância da faixa etária de 20 a 50 anos, somando $65,4 \%$ do total da amostra. Em seguida, aparece o grupo etário de 51 a 65 anos, que obteve também um percentual expressivo de 34,5\%. Com referência ao estado civil, 47,3\% dos participantes são casados, representando o maior percentual, vindo depois os solteiros, que perfazem 27,3\% dos casos. Quanto à escolaridade, há um predomínio daqueles com o ensino fundamental incompleto, representando $63,6 \%$ dos entrevistados, enquanto que 14,6\% são analfabetos e apenas 3,6\% têm o ensino superior completo e atuam na aldeia, como professores e diretores da escola. Observa-se que o nível de escolaridade é baixo, com um alto percentual de analfabetos, o que contribui para a colocação, no mercado de trabalho, em ocupaçōes/profissões não qualificadas e com baixos salários, atestando também o fato, destacado por pesquisadores da área - como Oliveira (2001), Langdon,(2007) e Moonen (2008) -, das precárias condições de vida desta população. 
A religião que se destaca entre os Potiguara é a católica, com 76,4\%, seguida pela protestante/evangélica, com $14,6 \%$, enquanto que apenas 1,8\% dos índios afirmaram a sua religiosidade ao Deus Tupã. De acordo com Palitot (2005), o catolicismo é a religião mais institucionalizada entre os Potiguara, remontando ao período colonial e sendo a fonte dos símbolos étnicos, históricos e territoriais, que são representados pelas velhas igrejas de Nossa Senhora dos Prazeres e São Miguel, com seus oragos e festas anuais. Esses dados demonstram uma mudança cultural no fator religião, com a apropriação de um saber institucionalizado, proporcionado pelas igrejas, decorrente da aculturação e da colonização das comunidades indígenas. Essa mudança pode ser identificada nas falas a seguir.

[...] Crianças que estão na sala de aula, mas que no sábado poderiam chegar aqui e a gente fazer trabalho de formação religiosa, na catequese. [...] É o pessoal da comunidade, tipo grupo de jovens, tem o grupo de jovens que faz parte da igreja, aí fica catequizando as pessoas, mostrando os prejuízos que causa aí até que parou agora... (S03; S07).

Em relação ao número de pessoas que constitui o núcleo familiar Potiguara, os percentuais são: $30,0 \%$, para quatro pessoas; $11,0 \%$, para cinco pessoas; $20,0 \%$, para seis pessoas; e 21,0\%, para mais de seis pessoas. Somando-se estes percentuais, observa-se que $52,0 \%$ dos entrevistados têm a família constituída a partir de cinco pessoas (famílias mais numerosas), enquanto 18,0\% possuem famílias de até três pessoas. Tais dados acarretam acréscimos na problemática social desta população, tendo em vista que entre os problemas advindos da situação socioeconômica precária dos Potiguara, destaca-se o percentual alto de famílias que sobrevivem de programas assistenciais, com um salário mínimo ou menos. Oliveira (2009) aponta que 90,9\% dos entrevistados (o que perfaz um total de 50 famílias) são usuários de algum programa do governo brasileiro. Dentre estes, 72,8\% são beneficiados com o Programa Bolsa Família, enquanto que $18,1 \%$ são favorecidos com a cesta básica, que é distribuída pela Fundação Nacional do Índio (FUNAI).

De acordo com Palitot (2005), grande parte da população Potiguara vive numa situação de pobreza extrema, numa economia de subsistência e com salários baixos nas usinas. Devido a estas questôes, os índios dessa região buscam na sua "indianidade" recursos financeiros para sua sobrevivência. No que se refere ao processo de aculturação, observamos dois movimentos na etnia Potiguara: por uma lado, estão hoje vivenciando um movimento significativo de valorização e intensificação de suas tradições, caracterizado por sua expressão 
étnica. Para tanto, eles adotaram algumas atividades práticas de conteúdos culturais denominada por alguns deles como resgate cultural, a saber: educação escolar indígena; reabilitação do uso da língua tupi, semana cultural Potiguara; semana dos jogos indígenas; dança do toré; e atividades alusivas ao Dia do Índio. Instituições como a FUNAI, as Secretarias municipais e estadual de Educação, a Universidade Federal da Paraíba (UFPB) e o Centro Federal de Tecnologia (CEFET/PB) atuam como parceiros para o desenvolvimento de atividades voltadas ao resgate cultural dos índios Potiguara.

Contudo, a dança do toré, que é uma prática realizada coletivamente e vem sendo mantida desde seus antepassados como símbolo de celebração de amizade entre os parentes de cada aldeia, hoje é utilizada fora da cultura indígena. O toré está sendo utilizado não para um ritual cultural, mas como atividade recreativa e como exploração financeira. É apresentado no Dia do Índio ou em ocasiōes especiais, quando pessoas (turistas, alunos, entidades oficiais) visitam a aldeia; este é um modo de vender seus produtos (artesanatos e alimentos). Os exemplos a seguir denotam esta situação: "[...] como atividade de recreação fazemos rituais que é a dança do toré [...] sempre dançamos o toré, no Dia do Índio, para comemorar entre os parentes, para o turista que vem na aldeia comprar o artesanato [...]”.

Aliado às péssimas condições socioeconômicas, ao turismo acentuado, à perda cultural e por ser uma droga lícita e extremamente incentivada, o álcool é amplamente consumido, fazendo parte de festividades e de relações sociais, tanto na população em geral como na comunidade indígena. Tal fato é observado nas falas que se seguem.

[...] Eu acho uma atitude muito fraca porque o povo não tem salário, não tem nada e
se junta um com outro, faz aquela vaquinha e ao invés de comprar um negócio, um
almoço melhor, compra um litro de cana e sai bebendo por aí. [...] Gasta o dinhei-
ro, aquele dinheirinho que eles pega, um dinheiro difícil. Porque nós não pega em
dinheiro, bem dizer pra fazer três quatro feiras. Dá graças a Deus quando arrumar
um trocadozinho pra fazer umas comprazinhas, pouquinha. A pessoa pega aquele
dinheiro divide em vez de se alimentar com ele e a família dele não, vai e extrapola
na bebida (S37; S47).

Com efeito, dos 55 índios entrevistados no presente trabalho, 41,8\% responderam que pelo menos um membro da família faz uso de bebida alcoólica. No que se refere às consequências do uso/abuso do álcool, 27,3\% disseram que a bebida traz problema para toda a família, e alguns informaram casos de óbito devido à cirrose hepática (5,5\%). As consequências mais citadas foram os 
problemas sociais, com 82,2\% (incluindo brigas/agressividade, com 49,0\%; problemas com o trabalho e acidentes automobilísticos); os problemas orgânicos, com 80,0\% (incluindo morte com 42,2\%; inchaço, problemas no fígado, fraqueza); os problemas familiares, com 35,6\%, e os problemas psicológicos, com $17,8 \%$, conforme exemplos a seguir.

Tem dia que ele às vezes não tem um dinheiro pra beber aí às vezes bebe até álcool, ele é um alcoólatra. [...] Não usam álcool nos rituais religiosos. Porque gostam de tomar a bichinha. É vício que eles têm. Depois que eles bebem, é só uma coisa que sai. Muitos provocam os outros. Alguns aguentam, outros não. Às vezes, brigam. Tem menino de quinze, dezesseis anos que já bebem. [...] Se a pessoa beber demais fica doente, só serve pra isso, pra beber muita, dá pra ficar doente, morre, como já morreu muito aqui, e tem uns que bebem e ficam com o pé inchado de beber, mas eles num deixam não, a cachaça, não. Num trabalha nem nada, fica nas vendas bebendo, e num vai trabalhar nem nada. O que traz é esse povo de fora que vem, vem vender aqui, que vem trazer esses negócios pra vender. $\mathrm{O}$ povo começa a beber aqui de doze anos, de dez anos as crianças tão bebendo aqui na venda, dez anos, doze anos, quinze, daí pra frente. É a cachaça mesmo, a cachaça às vezes cerveja também, eles bebem primeiro a cachaça, primeiro é a cachaça [...] (S42; S17; S19).

Estes resultados permitem afirmar que já existe um consumo abusivo de álcool na comunidade Potiguara, sustentado por vários fatores específicos - tais como alto contato interétnico, destruição da cultura indígena, baixas condições de vida e de saúde e inserção das aldeias nas cidades turísticas -, levando consigo todas as consequências do turismo acentuado. Existem fatores agravantes na comunidade Potiguara, dentre os quais podem ser destacados: (1) a proximidade entre as aldeias e os centros urbanos, acarretando uma aculturação desta população, com grande mestiçagem; (2) a existência de muitas usinas de álcool na região; e (3) a presença de um turismo cada vez mais acentuado, por se tratar de uma região litorânea. Tais fatos são observados nos discursos abaixo.

É um dos grandes problemas que a gente vem enfrentando ao longo dos anos. A presença do álcool nas áreas indígenas ela vem desde o início da invasão que sofremos, mas que com o passar do tempo ela só tem piorado.. Hoje a gente vê a diversidade de bebidas que temos na área que é um atrativo muito grande e é um dos grandes problemas que nós estamos enfrentando hoje [...] Antigamente aqui, existia cana, cachaça, mas o cara trazia de fora pra fazer um remédio assim, ou comprava mesmo numa venda na Baía, pra fazer um remédio qualquer desses, pisa a folha, ou qualquer outra medicação de mato. Aí botava dentro da cachaça e aquele povo mais velho defumava com o cachimbo, aquela cachaça dentro, aí você toma um pouquinho, ela mesma botasse um pouquinho, numa colher ou num copinho pequeno, toma isso aí. Aí depois que fazia, às vezes até banho, pronto, pra catapora, que o remédio dela antigamente era cachaça com o fumo. Tomava banho, passava o fumo, misturava o fumo dentro 
da cachaça e tomava banho. Fazia de conta que era um banho. Eu cansei de tomar

banho. Hoje em dia não usa mais não, vão pro médico, passa remédio (S15; S32).

Conceição (2007) verificou que, na percepção dos profissionais de saúde do Distrito Sanitário Especial Indígena (DSEI) Potiguara, diversos fatores contribuem para que os índios busquem o consumo de bebidas alcoólicas, entre os quais podem ser citados: a convivência social com o branco, a perda de identidade e cultura, a hereditariedade, a tristeza, a autoafirmação, os problemas econômicos, a ociosidade e a falta de trabalho, muitas vezes preguiça. Hoje há o consenso de a etiologia do alcoolismo ser multifatorial, havendo uma conjunção de fatores biológicos, psicológicos e sociais que agem concomitantemente na determinação da dependência; contudo, há uma culpabilização do sujeito, atribuindo a causa a questões de ordem pessoal. O estudo de Pimenta (2009) com uma amostra de 823 estudantes não-indígenas observou que o preconceito de não-indígenas contra os indígenas é alto e que existe uma correlação positiva entre responsabilizar os próprios índios por sua situação e o preconceito.

Castanha e Araújo (2006) destacam o uso do álcool como preocupante, uma vez que o alto índice de consumo continua crescendo assustadoramente, sobretudo entre os jovens, acarretando uma série de problemas, tanto de saúde quanto sociais. Esta situação é exemplificada nas falas a seguir.

Hoje o álcool está tendo um papel muito ruim dentro da nossa comunidade, principalmente com essa nova juventude, porque antigamente os mais velhos bebiam, mas tinham controle melhor, até porque as bebidas eram feitas por eles, outras misturadas com algumas ervas [...] Eu acho que pela moda, pela desocupação que hoje tem bastante na nossa área, antigamente todo mundo se interessava em cultivar, cultura, passava o dia inteiro nos roçados, outros na pesca e hoje num tem mais. Nossa mata devastada, a maré toda soterrada, aí eles ficam muitas vezes ociosos demais, principalmente a juventude fica muito ociosa e isso é um caminho que envereda pra bebida pra outros meios que a gente vê (S11; S50).

Segundo Souza, Oliveira e Kohatsu (2003), a discussão sobre o uso de bebida alcoólica na população indígena requer que se desvende uma rede de relações que envolvem esta prática. Para isto, faz-se necessário entender as múltiplas causas relacionadas ao processo de alcoolização no interior das comunidades indígenas. Entre os agravos que acometem os povos indígenas no Brasil, é notório que o consumo de bebidas alcoólicas tem-se intensificado, embora faltem dados mais precisos sobre as causas e consequências desse crescimento. Esta situação se aplica às atuais condiçôes dos índios Potiguara, pois, até a presente data, o DSEI não 
dispõe de nenhum registro (levantamento de dados) sobre o consumo de bebida alcoólica nesta etnia (OLIVEIRA, 2009).

De acordo com os estudos apresentados e as questôes analisadas, pode-se concluir que o consumo abusivo do álcool é uma realidade que traz inúmeras consequências danosas para a população indígena e, especificamente, para a comunidade Potiguara, com suas nuanças.

Através da presente pesquisa, pode-se perceber que existe uma boa parcela da comunidade já envolvida nesta problemática, sobretudo os jovens, e que o uso do álcool atinge não só os usuários diretos, mas também seus familiares. Observa-se também que o uso/abuso do álcool na comunidade Potiguara está não apenas disseminado, mas encontra-se desvinculado dos rituais e inserido na vida cotidiana, onde há o uso/abuso das substâncias destiladas, com prevalência da cachaça/cana/aguardente.

\section{Considerações finais}

O problema do uso abusivo de álcool tem sido alvo de estudos e pesquisas na atualidade devido a sua relevância, tendo em vista o fato de que suas consequências atingem nocivamente toda a sociedade. $\mathrm{O}$ alcoolismo é considerado um problema de saúde pública que atinge todas as camadas sociais, idades, sexo e etnia, vindo a afligir também a população indígena. Nesse sentido, esta pesquisa objetivou investigar o consumo do álcool na comunidade indígena Potiguara no Estado da Paraíba, visando a contribuir com a discussão e o estabelecimento de cuidados acerca dessa temática.

Constatou-se um alto consumo de álcool nesta comunidade, aliado a outras questôes histórico-culturais, como o processo de colonização e consequente aculturação indígena, e sociais, em que se destacam as precárias condiç̧óes de vida dessa população. Assim, observa-se a necessidade de empreender um trabalho de resgate da cultura, de prevenção e promoção da saúde, compreendendo-se a saúde em seu sentido mais amplo, que diz respeito não apenas ao tratamento de doenças, mas também ao melhoramento das condições de vida da população Potiguara.

Apesar dos importantes dados trazidos pela presente pesquisa, é importante considerar suas limitaçôes, sobretudo no que diz respeito à impossibilidade da generalização de seus resultados, tendo em vista que este estudo resulta de um contexto situacional específico, sendo de cunho exploratório. Desse modo, 
aponta-se a necessidade de serem desenvolvidos estudos mais amplos, abarcando

a temática da saúde e os aspectos socioculturais deste povo, envolvendo não apenas o consumo de álcool, mas também a presença de outras drogas.

\section{Referências}

AGUIAR, J.; SOUZA, J. Alcoolismo em População Terena no Estado do Mato Grosso do Sul - impacto da sociedade envolvente. In: SEMINÁRIO SOBRE ALCOOLISMO E DST/ AIDS ENTRE OS POVOS INDÍGENAS DAS REGIÕES SUL E SUDESTE, E DO MATO GROSSO DO SUL. Anais... Londrina, PR: Programa Municipal para DST/AIDS/ ALIA; Brasília, DF: Coordenação Nacional de DST/Aids, p. 117-124. 2001.

ASSIS, L.P.S. Da cachaça à libertação: mudanças nos hábitos de beber do povo Dâw no Alto Rio Negro. Revista Antropos, v. 1, n. 1, nov. 2007.

BARDIN, L. Análise de conteúdo. São Paulo: Martins Fontes, 1977.

BERTOLOTE, J.M. Conceitos em alcoolismo. In: RAMOS, S.P.; BERTOLOTE, J.M. Alcoolismo hoje. 3a ed. Porto Alegre: Artes Médicas, 1997.

BRASIL. Ministério da Saúde. Conselho Nacional de Saúde. Resolução no 196, de 10 de outubro de 1996. Aprova as Diretrizes e Normas Regulamentadoras de Pesquisas Envolvendo Seres Humanos. Brasília, DF, 1996.

- Ministério da Saúde. Conselho Nacional de Saúde. Resolução no 304, de 09 de agosto de 2000. Aprova as Normas para Pesquisas Envolvendo Seres Humanos: área de povos indígenas. Brasília, DF, 2000.

CARLOS, M.S. O papel das mulheres safristas no interior da unidade familiar: hierarquia e complementariedade. Monografia. 2006. 109p. (Graduação) - UNISC, Florianópolis, 2006.

CASTANHA, A.R.; ARAÚJO, L.F. Álcool e agentes comunitários de saúde: um estudo das representaçôes sociais. Psico - USF, v. 11, n. 1, p. 85-94, jan./jun. 2006.

COIMBRA JR., C.E.A; SANTOS, R.V. Saúde, minoria e desigualdade: algumas teias de inter-relações, com ênfase nos povos indígenas do Brasil. Rev Ciência e Saúde Coletiva, Rio de Janeiro, v. 5, n. 1, p. 125-132, 2000.

CONCEIÇÃO, J.J. A percepção dos profissionais de saúde da área indígena Potiguara sobre o consumo de bebidas alcoólicas pelos indios. 2007. 72p. Monografia (Especialização) - Universidade Federal da Paraíba, João Pessoa, 2007.

FUNDAÇÃO NACIONAL DO ÍNDIO. Instrução Normativa no 01/95/PRESI/FUNAI. Normas que disciplinam o ingresso em terras indigenas com finalidade de desenvolver pesquisa científica. Brasília, 1995.

FUNDAÇÃO NACIONAL DE SAÚDE. Politica Nacional de Atenção à Saúde dos Povos Indígenas. Brasília, 2000. 

. DSEI Potiguara. Plano Distrital de Saúde Indígena 2008-2010. João Pessoa, PB, 2007.

. DSEI Potiguara. Relatório de produção mensal das equipes de saúde dos Polos-Base. João Pessoa, PB, 2008.

LANGDON, E.J. O que beber, como beber e quando beber: o contexto sociocultural no alcoolismo entre as populações indígenas. In: SEMINÁRIO SOBRE ALCOOLISMO E VULNERABILIDADE ÀS DST/AIDS ENTRE OS POVOS INDÍGENAS DA MACRORREGIÃO SUL, SUDESTE E MATO GROSSO DO SUL. Anais... Brasília, DF, 2001. p.83-97.

LANGDON, E.J. Diversidade cultural e os desafios da Política Brasileira de Saúde do Índio. Editorial Especial. Saúde e Soc, São Paulo, v. 16, n. 2, p. 7-12, ago. 2007.

LARANJEIRA, R.; PINSKY, L. O alcoolismo. São Paulo: Contexto, 2000. 61p.

LINS, M.H.S.F.; VASCONCELOS, O.O. A questão indígena no nordeste. In: CONGRESSO BRASILEIRO DE EXTENSÃO UNIVERSITÁRIA. 2., Anais... Belo Horizonte, set. 2004.

MOONEM, F. Os indios Potiguara da Paraíba. 2oed. dig. aum. Recife, 2008. 41p.

OPAS/OMS. Relatório sobre a Saúde no Mundo. São Paulo: Gráfica Brasil, 2001.

OLIVEIRA, M. Alcoolismo entre os Kaingáng: do sagrado e lúdico à dependência. In: SEMINÁRIO SOBRE ALCOOLISMO E VULNERABILIDADE ÀS DST/AIDS ENTRE OS POVOS INDÍGENAS DA MACRORREGIÃO SUL, SUDESTE E MATO GROSSO DO SUL. Anais... Brasília, 2001.

OLIVEIRA, R.C.C. Representaçôes sociais sobre a situação de vida, saúde e doença na concepção indígena Potiguara. 2009. 133f. Dissertação (Mestrado em Enfermagem). Universidade Federal da Paraíba, João Pessoa, PB, 2009.

PALITOT, E. M. Parecer Antropológico DSEI Potiguara. Relatório Projeto FUNASA/PRODOC, João Pessoa, PB, 2005.

PIMENTA, R.P.B. Atribuição de responsabilidade da atual situação do indio e o preconceito contra os povos indígenas brasileiros. Dissertação (mestrado em Psicologia) - Universidade Católica de Goiás, Departamento de Psicologia, Goiás, 2009.

SOUZA, J.A.; OLIVEIRA, M.; KOHATSU, M. O uso de bebidas alcoólicas nas sociedades indígenas: algumas reflexões sobre os Kaingáng da Bacia do Rio Tibagi, Paraná. In: ______. (Org.). Epidemiologia e Saúde dos Povos Indígenas do Brasil. Rio de Janeiro: Fiocruz, 2003. p. 149-167.

SOUZA, M.; GARNELO, L. Quando, como e o que se bebe: o processo de alcoolização entre populações indígenas do Alto do Rio Negro, Brasil. Cad de Saúde Pública, Rio de Janeiro, v. 23, n. 7, p. 1640-1648, 2007. 


\section{Abstract}

Implications of alcohol abuse and consumption in the Potiguara indigenous community

Due to the growth of usage and alcohol abuse in indigenous populations of Brazil, this research aims to investigate alcohol consumption in the Potiguara community, in the State of Paraíba, considering its specific cultural and regional differences of ethnicity. This is an exploratory field study. The sample consisted of 55 Indians, aged over 18 years and of both sexes. The instrument was a semistructured interview administered individually. For data analysis, we used the SPSS software and qualitative analysis. The results revealed that $41.8 \%$ of the sample have at least one family member who uses alcohol, mostly distilled, and that use starts at an early age, being detached from the culture and rituals. Of the respondents $27.3 \%$ said that drinking brings many problems for the entire family, including death. We can concluded that in the indigenous population studied, consumption of alcoholic beverages is abused and starts early; so a more effective prevention and recovery of the culture of this community are needed.

> Key words: indigenous health; alcoholism; Potiguara indigenous; social conditions; culture. 